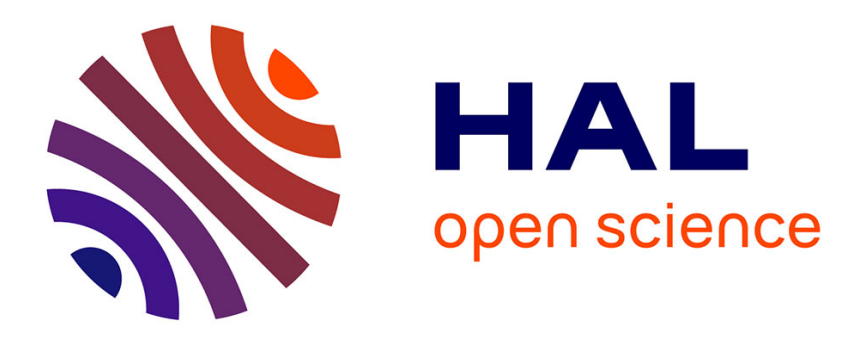

\title{
Extended Generation Profile - E.B.I.C. Model
}

\author{
S. Guermazi, A. Toureille, C. Grill, B. El Jani, N. Lakhoua
}

\section{To cite this version:}

S. Guermazi, A. Toureille, C. Grill, B. El Jani, N. Lakhoua. Extended Generation Profile - E.B.I.C. Model. Journal de Physique III, 1996, 6 (4), pp.481-490. 10.1051/jp3:1996136 . jpa-00249471

\section{HAL Id: jpa-00249471 https://hal.science/jpa-00249471}

Submitted on 1 Jan 1996

HAL is a multi-disciplinary open access archive for the deposit and dissemination of scientific research documents, whether they are published or not. The documents may come from teaching and research institutions in France or abroad, or from public or private research centers.
L'archive ouverte pluridisciplinaire HAL, est destinée au dépôt et à la diffusion de documents scientifiques de niveau recherche, publiés ou non, émanant des établissements d'enseignement et de recherche français ou étrangers, des laboratoires publics ou privés. 


\title{
Extended Generation Profile - E.B.I.C. Model
}

S. Guermazi $\left({ }^{1, *}\right)$, A. Toureille $\left({ }^{2}\right)$, C. Grill $\left({ }^{3}\right)$, B. El Jani $\left({ }^{4}\right)$ and N. Lakhoua $\left({ }^{5}\right)$

(1) Département de Physique, Institut Préparatoire aux Études d'ingénieurs de Sfax, BP 805 Sfax, Tunisia

$\left({ }^{2}\right)$ L.E.M., Université Montpellier 2, Place Eugène bataillon, 34000 Montpellier, France

$\left({ }^{3}\right)$ Laboratoire de Microscopie électronique, Université Montpellier 2, Place Eugène bataillon, 34000 Montpellier, France

$\left({ }^{4}\right)$ Département de Physique, Faculté des Sciences de Monastir, Tunisia

(5) Département de Génie électrique, École Nationale d'Ingénieurs de Sfax, Tunisia

(Received 15 June 1995, revised 16 November 1995, accepted 23 January 1996)

PACS.72.20.Jv - Charge carriers: generation, recombination, lifetime, and trapping.

\begin{abstract}
We have developed a model for the calculation of the induced current due to an electron beam with an extended generation profile. As well as the number of absorbed and diffuse electrons as a function of the depth, the generation profile takes into account the lateral diffusion and the effect of defects, dislocations and recombination surfaces. The expression from the Electron Beam Induced Current (EBIC) is obtained by solving the continuity equation in permanent regime by the Green function method. In the case of a Schottky diode $\mathrm{Au} / \mathrm{InP}$, obtained by ionic scattering followed by a quick thermal treatment, the induced current profile is compared to the theoretical profiles whose analytical expressions are given by Van Roosbroeck and Bresse. The experimental current profile, measured by S.E.M provided us with the calculation of the diffusion length of the minority carriers, $L_{\mathrm{n}}=1 \mu \mathrm{m}$. The theoretical curve obtained from the proposed model is in good agreement with the experimental one for a surface recombination velocity of $10^{4} \mathrm{~cm} \mathrm{~s}^{-1}$. Our results are found to be consistent with those obtained by other experimental techniques on the same samples.
\end{abstract}

Résumé. - Nous avons dévoloppé un modèle de calcul du courant induit par un faisceau d'électrons avec un profil de génération élargi. Le profil de génération tient compte, en plus du nombre d'électrons absorbés et du nombre d'électrons diffusés en fonction de la profondeur, de la diffusion latérale (en prenant en considération la diffusion angulaire), de l'effet des défauts, des dislocations et de la recombinaison à la surface. L'expression analytique du courant induit E.B.I.C est déterminée par résolution de l'équation de continuité en régime permanent par la méthode des fonctions de Green. Le profil de courant induit obtenu dans le cas d'une diode Schottky $\mathrm{Au} / \mathrm{InP}$ dopé $\mathrm{p}$ et fabriqué par implantation suivit d'un recuit, est comparé au profil de courant théorique dont l'expression analytique est explicitée par Van Roosbroeck et Bresse. Le profil de courant expérimental, mesuré par un microscope électronique à balayage, nous a permis de calculer la longueur de diffusion des porteurs minoritaires $L_{\mathrm{n}}=1 \mu \mathrm{m}$. La courbe théorique, tracée à partir du modèle proposé, est en bon accord avec la courbe expérimental pour une vitesse de recombinaison à la surface de $10^{4} \mathrm{~cm} \mathrm{~s}^{-1}$. Ces résultats sont conformes avec ceux obtenus par d'autres techniques expérimentales sur les mêmes échantillons.

(*) Author for correspondence (Fax: (216) 4246 347).

(C) Les Éditions de Physique 1996 


\section{Introduction}

Van Roosbroeck [1] and Bresse [2] showed that the induced current collected by a plane junction of finite thickness is given by:

$$
I_{\mathrm{cc}}=q G_{0} \frac{2}{\pi} \frac{S}{H} K_{1}\left(X_{0}\right)
$$

where $K_{1}$ is the first order Bessel function of second kind, $S$ is the reduced surface recombination velocity, $X_{0}$ is the reduced coordinate of a source point, $H$ is the reduced depth of the bulk and $G_{0}$ is the total generation rate within the generation volume. They showed that the induced current generated by an electron beam and collected within the depletion layer for a vertical junction, is of the form:

$$
I_{Z C} \propto \mathrm{e}^{-\frac{x_{0}}{L}}
$$

where $x_{0}$ is the position of the incident beam electrons and $L$ is the minority carrier diffusion length.

Berz and Kuiken [3] generalized Bresse's result to arbitrary values of the recombination surface velocity $S$. The paper includes Van Roosbroeck and Bresse's solutions as special cases with $Z_{1}=0$, and $S=0, \infty$, respectively. Donolato [4] has given an expression for the short circuit current for the idealized case of uniform doping and uniform density of recombination centres. He used an alternative integral representation for the induced current profile due to a point source at a finite depth which makes use of elementary functions only. He demonstrated that this form is convenient both for discussing the case of an extended generation and for taking into account the finite sample thickness.

The analysis given by Oldwing Von Roos [5] has some similarity with Donolato, since he applied the Fourier techniques to the solution of the continuity equation with appropriate boundary conditions. His work showed that the Donolato series converge far slower than the integral over elementary functions.

In the present sequel, we propose a $2-\mathrm{D}$ generation rate model for the calculation of the collected induced current within the junction. We compare our results to those found experimentally. Then, we turn our scope to the determination of the diffusion length of the excess minority carriers generated by the electron beam. We also look at the surface recombination velocity from both the Van Roosbroeck and Bresse model (classical one) and that proposed here, in the case of a Schottky diode Au/InP obtained by implantation and quick thermal treatment. A comparison study between these models is then presented.

\section{Description of the Used Generation Model}

Our proposed generation profile of electron-hole pairs includes the lateral diffusion, taking into account the incident electron angular diffusion, the effect of defects, dislocations and surface recombinations, as well as the number of absorbed and diffused electrons in depth. The electron-hole pair generation volume is an onion-shaped volume, with the incident beam electron direction as a symmetry axis and containing $x_{0}$. The generation rate only depends on the incident beam energy and the nature of the sample. Hence, the lateral diffusion is described by a Gaussian function of $\left(x-x_{0}\right)$, obtained by solving the equation of Bothe [6]. Whereas, the electron diffusion for a given depth has a form depending on the energy loss as a function 
of depth as proposed by Kanaya and Okayama [7]. The generation profile can be written as a convolution product of two functions $[8,9]$ :

$$
\begin{aligned}
g\left(x-x_{0}, z\right) & =\frac{(1-\bar{R}) E_{0}}{E_{\mathrm{p}}} \frac{1}{R_{\mathrm{K}}} \Phi\left(\frac{z}{R_{\mathrm{K}}}\right) \frac{\alpha}{\sqrt{\pi}} \mathrm{e}^{-\alpha^{2}\left(x-x_{0}\right)^{2}} \\
R_{\mathrm{K}} & =\frac{A E_{0}^{\frac{5}{3}}}{5 \times 2^{\frac{5}{3}} \lambda_{\mathrm{s}} \pi a^{\frac{1}{3}} \mathrm{e}^{\frac{10}{3}} \mathcal{N} Z_{\rho}}
\end{aligned}
$$

where $\Phi\left(\frac{Z}{R_{\mathrm{K}}}\right)$ is the depth dose function and $R_{\mathrm{K}}$ is the maximum range presented by Kanaya [7]; $a$ is the Bohr radius of the Hydrogen atom; $Z$ is the atomic number of the target; $\mathcal{N}$ is the Avogadro number, $\rho\left(\mathrm{g} \mathrm{cm}^{-3}\right)$ is the density of the target; $A(g)$ is the atomic weight, $\bar{R}$ is the backscattered electrons coefficient, $E_{0}(\mathrm{eV})$ is the incident beam energy, $E_{\mathrm{p}}(\mathrm{eV})$ is the energy gap and $\alpha$ is a parameter to be determined experimentally.

\section{Theoretical Study}

We will investigate the case of a vertical junction Silicon doped Schottky diode Au/InP. The plane of the junction is perpendicular to the surface and the electron beam scans the surface perpendicular to the depletion layer (along the $x$-axis) (Fig. 1).

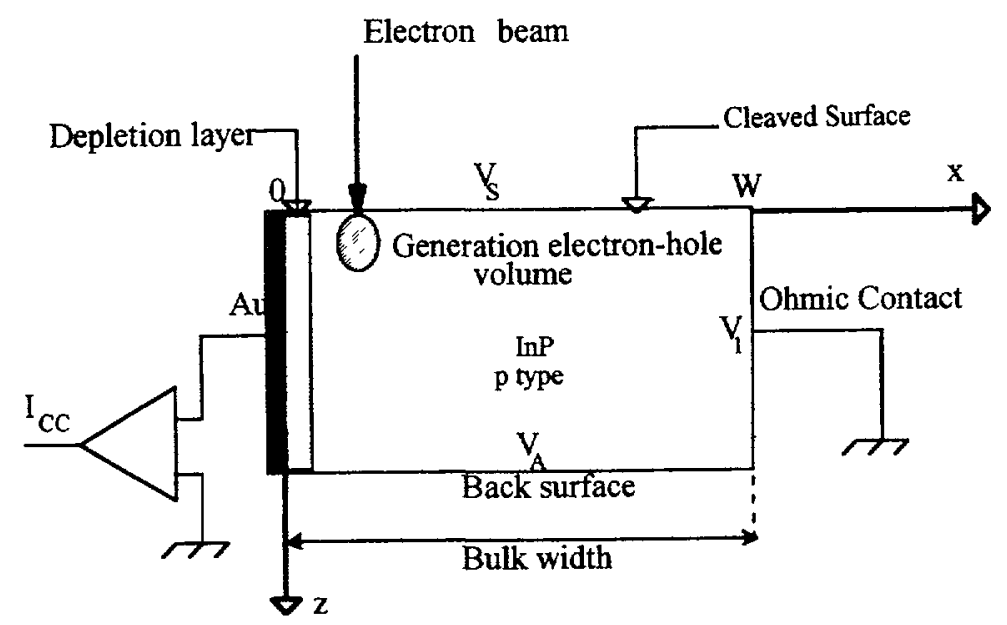

Fig. 1. - Physical model.

The steady-state continuity equation for the excess minority carrier density created within the region $p$ is then:

$$
\nabla^{2}[\Delta n(r)]-\frac{\Delta n(r)}{L_{\mathrm{n}}^{2}}=-\frac{1}{D_{\mathrm{n}}} g(r)
$$

where $L_{\mathrm{n}}$ is the diffusion length; $D_{\mathrm{n}}$ is the diffusion constant of the excess minority carriers and $g(r)$ is the generation rate of the excess minority carriers. 
The boundary conditions associated with this physical model are:

$$
\begin{aligned}
& z=0, \quad D_{n} \frac{\partial \Delta n}{\partial z}=V_{\mathrm{s}} \Delta n \quad \text { (Neuman equation) } \\
& z=H, \quad D_{n} \frac{\partial \Delta n}{\partial z}=-V_{\mathrm{A}} \Delta n \quad \text { (Neuman equation) } \\
& x=0, \quad \Delta n=0 \quad \text { (Dirichlet equation) } \\
& x=w_{1}, \quad D_{n} \frac{\partial \Delta n}{\partial x}=V_{1} \Delta n \quad \text { (Neuman equation) }
\end{aligned}
$$

where $V_{\mathrm{s}}, V_{\mathrm{A}}$ and $V_{1}$ are the recombination velocities at the scanned surface, the back face and the ohmic contact respectively. The Green function associated with equation (4), where an elementary source located at the point of coordinates $\left(x^{\prime}, y^{\prime}\right)$ in the electron-hole generation volume, and which satisfies the boundary conditions (5) is [10]:

$$
\begin{aligned}
& G\left(x, x^{\prime} ; z, z^{\prime}\right)=\frac{1}{D_{\mathrm{n}}}=\sum_{k} \frac{l_{k}}{l_{k} H+\sin \left(l_{k} H\right)} \frac{\cos \left(l_{k}\left(z-\frac{H}{2}\right)\right) \cos \left(l_{k}\left(z^{\prime}-\frac{H}{2}\right)\right)}{\mu_{k}\left(\mathrm{e}^{\mu_{k} w_{1}}+K_{1} \mathrm{e}^{-\mu_{k} w_{1}}\right)} \\
& {\left[\mathrm{e}^{-\mu_{k}\left(\left|x-x^{\prime}\right|-w_{1}\right)}-\mathrm{e}^{-\mu_{k}\left(x+x^{\prime}-w_{1}\right)}+k_{1} \mathrm{e}^{\mu_{k}\left(x+x^{\prime}-w_{1}\right)}-k_{1} \mathrm{e}^{\mu_{k}\left(\left|x-x^{\prime}\right|-w_{1}\right)}\right]} \\
& \text { where } \\
& \mu_{k}=\sqrt{l_{k}^{2}+\frac{1}{L_{\mathrm{n}}^{2}}} \quad \text { et } \quad K_{1}=\frac{\mu_{k}-\frac{V_{1}}{D_{\mathrm{n}}}}{\mu_{k}+\frac{V_{1}}{D_{\mathrm{n}}}}
\end{aligned}
$$

The collection probability of the minority carriers generated at the point $\left(x^{\prime}, z^{\prime}\right)$ at the junction level is defined by:

$$
\begin{aligned}
Q\left(x^{\prime}, z^{\prime}\right)= & \sum_{k} \frac{2 \sin \left(l_{k} \frac{H}{2}\right)}{l_{k} H+\sin \left(l_{k} H\right)} \frac{1}{\mathrm{e}^{\mu_{k} w_{1}}+K_{1} \mathrm{e}^{-\mu_{k} w_{1}}} \\
& {\left[\mathrm{e}^{-\mu_{k}\left(x^{\prime}-w_{1}\right)}+K_{1} \mathrm{e}^{\mu_{k}\left(x^{\prime}-w_{1}\right)}\right] \cos \left(l_{k}\left(z^{\prime}-\frac{H}{2}\right)\right) }
\end{aligned}
$$

In the case of an impulse located in the junction plane $(x=0)$, we suppose that all the carriers created within the depletion layer are collected by the junction field [11], such that the collection probability of the minority carriers within the depletion layer equals 1.

For an extended generation, the collected current in the level of the vertical or horizontal junction is obtained from the collection probability of the minority carriers due to a Dirac impulse, by integrating the minority carrier generation volume.

$$
I_{\mathrm{cc}}=\mathrm{e} \iint_{V} Q\left(x^{\prime}, z^{\prime}\right) g\left(x^{\prime}, z^{\prime}\right) \mathrm{d} x^{\prime} \mathrm{d} z^{\prime}
$$

where $V$ is the generation volume. Hence, the expression of the induced current collected within the vertical junction is:

$$
\begin{aligned}
& I_{\text {cc }}=\frac{\mathrm{e}(1-\bar{R}) E_{0}}{E_{\mathrm{p}}} \frac{1}{R_{\mathrm{K}}} \frac{\alpha}{\sqrt{\pi}} \sum_{k} \frac{2 \sin \left(l_{k} \frac{H}{2}\right)}{l_{k} H+\sin \left(l_{k} H\right)} \frac{1}{\mathrm{e}^{\mu_{k} W_{1}}+K_{1} \mathrm{e}^{-\mu_{k} W_{1}}} \\
& {\left[\int_{x_{0}-\alpha}^{x_{0}+\alpha}\left(\mathrm{e}^{-\mu_{k}\left(x^{\prime}-w_{1}\right)}+K_{1} \mathrm{e}^{\mu_{k}\left(x^{\prime}-w_{1}\right)}\right) \mathrm{e}^{-\alpha^{2}\left(x-x_{0}\right)^{2}} \mathrm{~d} x\right]\left[\int_{0}^{R_{\mathrm{K}}} \Phi\left(\frac{z}{R_{\mathrm{K}}}\right) \cos l_{k}\left(z-\frac{H}{2}\right) \mathrm{d} z\right]}
\end{aligned}
$$


Then, the analytical expression of the induced current generated by an electron beam and collected within the depletion layer for vertical junction is of the form:

$$
I_{\mathrm{ZC}} \propto \mathrm{e}^{-\alpha^{2} x_{0}^{2}}
$$

\section{Experimental Results}

Our sample is a Schottky diode deposited on Silicon doped $\mathrm{p}$ type Indium phosphide, by ionic scattering $(\mathrm{Au} / \mathrm{InP})$. During the preparation of the substract InP, the doping atoms ( $\mathrm{Si}$ ) are scattered by an ionic scatterer. They are produced using an ionic source which is then accelerated using a particle accelerator $(30 \mathrm{kV})$.

We thermally treated our sample (fast thermal treatment at $800{ }^{\circ} \mathrm{C}$ ) in order to avoid the degradation of the InP substrate during the doping by diffusion on the lat tice defects caused by the ionic bombarding and to ensure the migration of the scattered atoms from interstitial sites to substitutional sites. The energy of the incident electron beam is of the order of $E_{0}=25 \mathrm{KeV}$. The circuit is shown in Figure 1.

Figure 2 shows an example of the results obtained by an on line scanning.

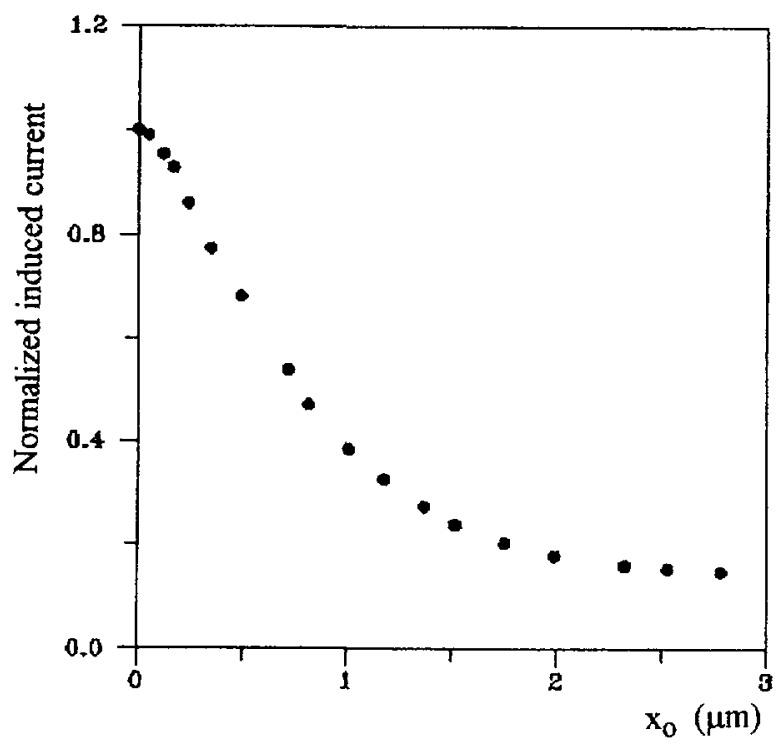

Fig. 2. - Normalized induced current measured by S.E.M.E.B.I.C. mode on an Au/InP Schottky diode.

The curve of the normalized induced current versus the incident beam position decreases exponentially from a maximum at the beginning of the depletion layer.

4.1. W. VAn Roosbroeck and J.F. BResse Model. - The induced current generated by an electron beam and collected within the depletion layer for a vertical junction is of the form (2).

$$
I_{\text {ZC }} \propto \mathrm{e}^{-\frac{x_{0}}{L}}
$$




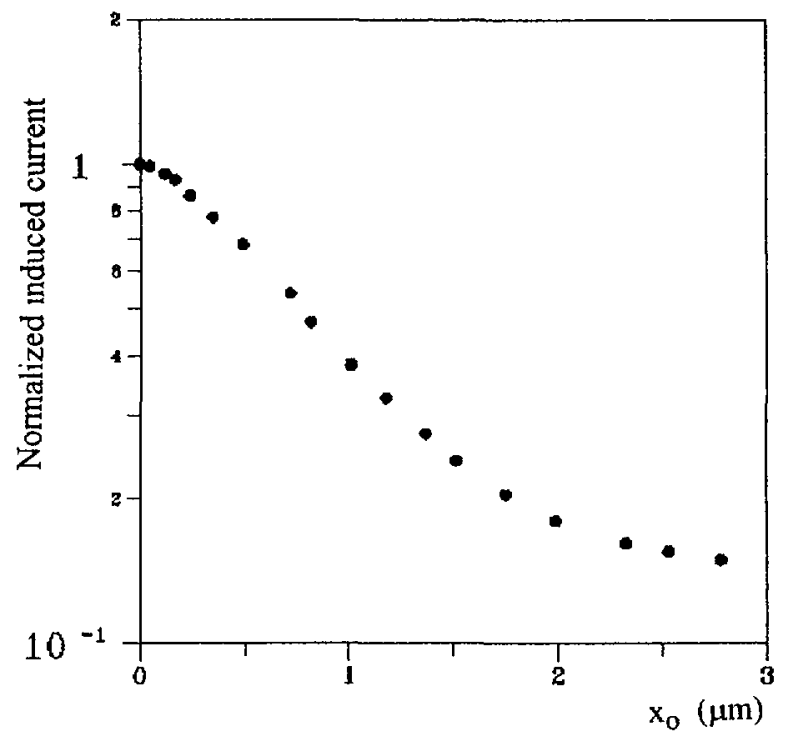

Fig. 3. - Normalized induced current versus incident beam position.

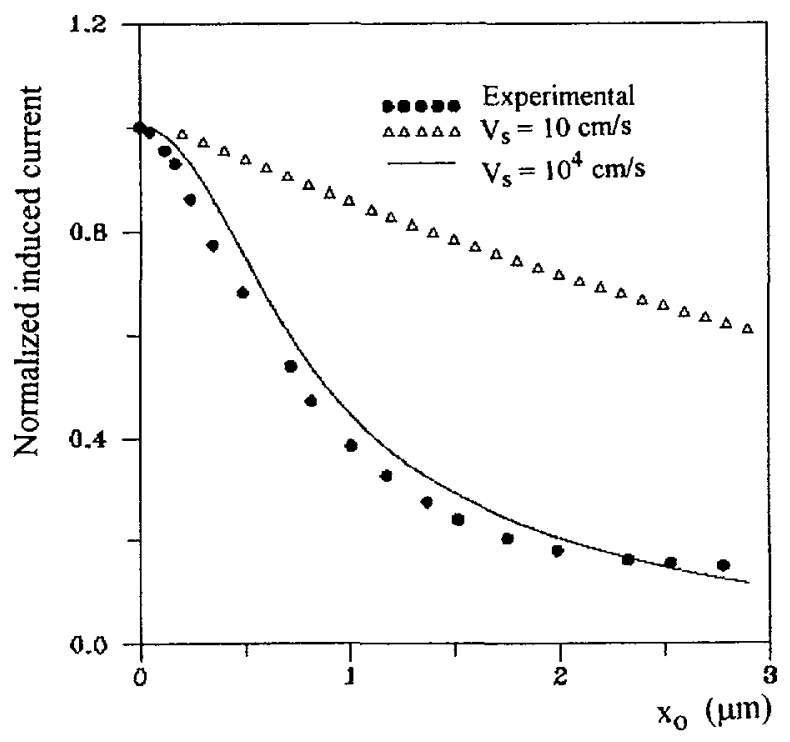

Fig. 4. - Normalized induced current for $L_{\mathrm{n}}=2.3 \mu \mathrm{m}$ and different surface recombination velocity $V_{s}$.

The experimental values are reported in Figure 3 on a semi-log scale as a function of $x_{0}$. The diffusion length of the generated minority carriers is given by the inverse of the slope at the linear part of the curve (Fig. 3). Figure 3 gives $L_{\mathrm{n}}=2.3 \mu \mathrm{m}$. 


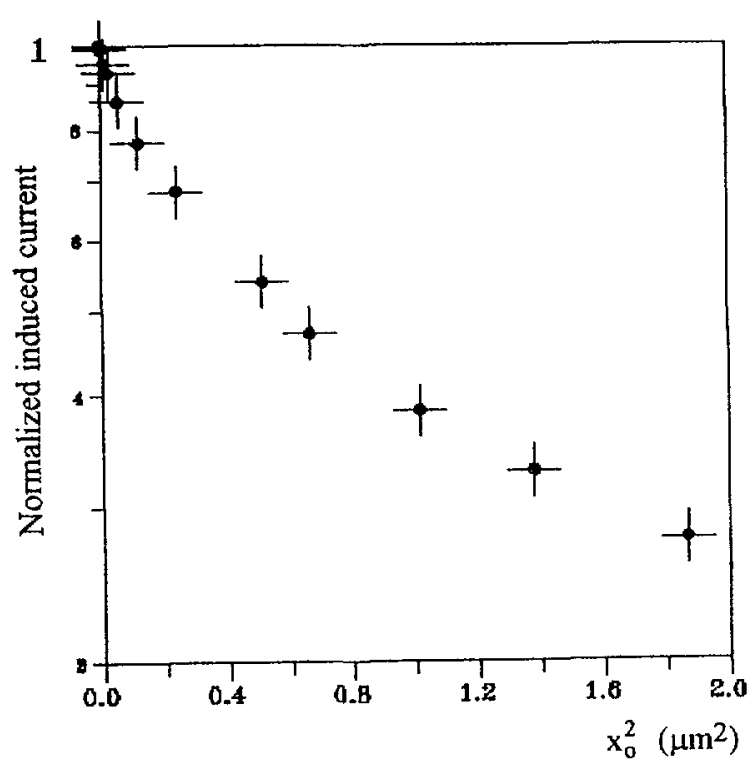

Fig. 5. - Normalized induced current versus squared incident beam position.

In width of bulk, we find a second linear part for which $L_{\mathrm{n}}=13.5 \mu \mathrm{m}$. This is probably due to the presence of a darkness current created by an induced thermal vibration caused by the electron beam.

To determine the surface recombination velocity of the sample, we numerically calculated the induced current from Bresse's equation (1) [2] for two values of recombination velocities. The curves obtained were then compared to the experimental curve. All the curves are shown in Figure 4. Only the curve corresponding to $V_{\mathrm{s}}=10^{4} \mathrm{~cm} \mathrm{~s}^{-1}$ fits with the experimental one. That of $V_{\mathrm{s}}=10 \mathrm{~cm} \mathrm{~s}^{-1}$, which is approximately linear, is as yet to be accounted for.

4.2. The Proposed Model. - The induced current generated by an electron beam and collected within the depletion layer for a vertical junction is of the form (10):

$$
I_{\mathrm{ZC}} \propto \mathrm{e}^{-\alpha^{2} x_{0}^{2}}
$$

The experimental values of the induced current are reported in Figure 5 on a semi-logarithmic scale as a function of $x_{0}^{2}$. The curve has a linear decreasing shape. The diffusion length of the generated minority carriers has been found to be $L_{\mathrm{n}}=1 \mu \mathrm{m}$ from the linear part of the square root inverse slope of the curve.

In width of bulk, we find a second linear part for which $L_{\mathrm{n}}=3 \mu \mathrm{m}$. This is probably due to the presence of a darkness current, created by an induced thermal vibration as a result of the electron beam.

The induced current is obtained numerically from equation (9) for two values of the recombination velocities. Figure 6 shows that there is a good agreement between the theoretical curve $\left(V_{\mathrm{s}}=10^{4} \mathrm{~cm} \mathrm{~s}^{-1}\right)$ and the experimental result. 


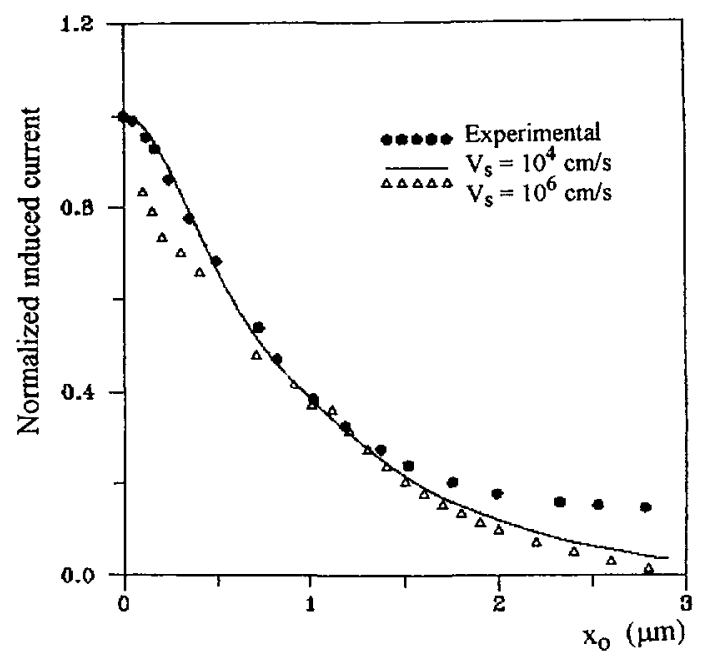

Fig. 6. - Normalized induced current for $L_{\mathrm{n}}=1 \mu \mathrm{m}$ and different surface recombination velocity $V_{\mathrm{s}}$.

\section{A Comparative Study and Discussion}

In Figure 7, the experimental, the classical, as well as our proposed model results, are plotted on the same graph. Our curve coincides totally with the experimental one except for distances far from the depletion layer $\left(x_{0}>1.5 \mu \mathrm{m}\right)$. This divergence is probably due to the darkness current which is added to the E.B.I.C current in that region. Such a current is due to thermal vibration induced by the energetic incident beam electrons.

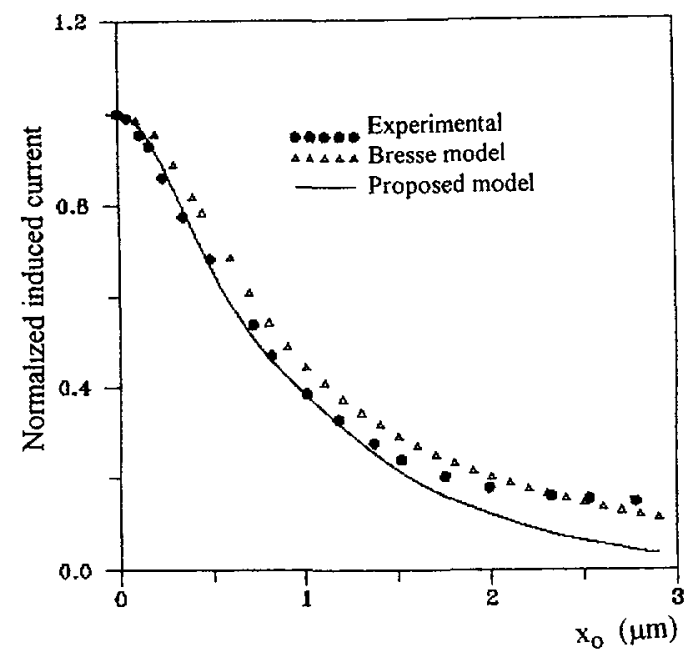

Fig. 7. - Normalized induced current from different models for $V_{\mathrm{s}}=10^{4} \mathrm{~cm} \mathrm{~s}^{-1}$ 
On the other hand, the classical model curve and the experimental one start with the same current at the beginning of the depletion layer to diverge from each other with the width of bulk.

The Table below provides us with a comparison of both the Olding Van Roos and Bresses and the proposed EBIC technique model with other techniques (Raman spectroscopy, photoluminescence intensity and Hall effect).

\begin{tabular}{|c|c|c|}
\hline & $\begin{array}{c}L_{\mathrm{n}} \\
(\mu \mathrm{m})\end{array}$ & $\begin{array}{c}V_{\mathrm{s}} \\
\left(\mathrm{cm} \mathrm{s}^{-1}\right)\end{array}$ \\
\hline $\begin{array}{c}\text { W. Olding Van Roos and J.F. } \\
\text { Bresse Model }\left(\mathrm{e}^{\frac{-x_{0}}{L}}\right)\end{array}$ & 2.3 & $\approx 10^{4}$ \\
\hline Proposed model $\left(\mathrm{e}^{-\frac{x_{0}^{2}}{L^{2}}}\right)$ & 1 & $10^{4}$ \\
\hline $\begin{array}{c}\text { Results of other experimental } \\
\text { techniques }[12-14]\left(^{*}\right)\end{array}$ & 1 & $10^{4}-10^{5}$ \\
\hline
\end{tabular}

$\left({ }^{*}\right)$ depending on minority carrier concentrations.

It is evident that our model is more realistic than that of Van Roosbroeck and Bresse. It is more convenient to describe a real EBIC current of the sample.

$$
\begin{aligned}
& \text { Hence, the EBIC current in the depletion layer has to be described by } e^{\frac{x_{0}^{2}}{L^{2}}} \text { rather than } \\
& \mathrm{e}^{-\frac{x_{0}}{L}} \text {. }
\end{aligned}
$$

The EBIC induced current profile, calculated from the developed model, fits better with the experimental one obtained by S.E.M than those of Van Roosbroeck and Bresse. Moreover, our results are in good agreement with experimental results obtained from other techniques [12-14]. we believe that our work is a generalization of that of Van Roosbroeck and Bresse and gives a more realistic picture of the process.

We are, at present adopting our extended generation profile electrou-hole pairs model to other structures of different doping and composition for both vertical and horizontal junctions.

\section{References}

[1] Van Roosbroeck W., J. Appl. Phys. 26 (1955) 380-391.

[2] Bresse J.F., J. Micros. Spectrosc. Electrons 6 (1981) 17-36.

[3] Berz F. and Kuiken H.K., Solid. St. Electronics 19 (1976) 437-445.

[4] Donalato C., Solid. St. Electronics 25 (1982) 1077-1081.

[5] Luke K.L. and Von Roos O., Solid. St. Electronics 21 (1983) 901-906.

[6] Bothe W., Silzungsber Heideberger A., Kad 7, Abhandlung (1951) 307.

[7] Kanaya K. and Okayama S., J. Phys. D. Appl. Phys. 5 (1972) 43-58.

[8] Guermazi S., Chaari J. and Lakhoua N., Influence de l'étendue du profile de génération des pairs électron-trous sur le courant induit EBIC, Journées de Physique et Technologie des Matériaux Avancés (Hammamet 18-19 Mars 1994) pp. 30-35. 
[9] Guermazi S., Chaari J., Fakhfakh Z. and Lakhoua N., Calcul du courant EBIC dans un échantillon de Silicium polycristallin par des modèles de générations élargis, Journées Maghrébine des Sciences des Matériaux 94 (Casablanca 23-24 Novembre 1994) pp. 128132.

[10] Morse and Feshbach, "Methodes of theorical physics", Chap. 7, part I (New York, TorontoLondon, 1953).

[11] Leamy H.J., J. Appl. Phys. 53 (1982) R51-R80.

[12] Jensen B., J. Appl. Phys. 50 (1979) 5800-5804.

[13] Bachmann K.J., Ann. Rev. Mater. Sct. 11 (1981) 441-484.

[14] Nakamura T. and Katod T., J. Appl. Phys. 55 (1984) 3064-3067. 